\title{
PENINGKATAN PRESTASI BELAJAR MATEMATIKA \\ SISWA SMK MELALUI MODEL QUANTUM TEACHING \\ MELIBATKAN MULTIPLE INTELLIGENCE
}

\author{
Sofia Edriati, Hamdunah, dan Riri Astuti \\ Program Studi Pendidikan Matematika STKIP PGRI Sumatera Barat \\ email: sofia.edriati@yahoo.co.id
}

\begin{abstract}
Abstrak: Penelitian ini bertujuan untuk mengetahui peningkatan prestasi belajar matematika dalam pembelajaran yang menggunakan model quantum teaching yang diterapkan berdasarkan multiple intelligences yang dimiliki siswa. Penelitian ini merupakan penelitian eksperimen dengan rancangan Pretest and Posttest Group. Populasi penelitian adalah siswa kelas XI Jurusan Jasa Boga salah satu SMK di Kota Padang. Sampel sebanyak satu kelas dipilih secara cluster random sampling. Data diperoleh melalui angket multiple intelligence dan teknik pretes-postes. Data angket dianalisis secara kualitatif dan data pretes-postes dianalisis menggunakan skor gain ternormalisasi. Hasil penelitian menunjukkan bahwa terjadi peningkatan prestasi belajar matematika setelah mengikuti proses pembelajaran menggunakan model quantum teaching yang melibatkan multiple intelligence siswa.
\end{abstract}

Kata Kunci: Quantum Teaching, Multiple Intelligence, prestasi belajar

\section{THE IMPROVEMENT OF SMK STUDENTS' ACHIEVEMENT \\ IN MATHEMATICS THROUGH THE IMPLEMENTATION OF QUANTUM TEACHING MODEL FOCUSING ON MULTIPLE INTELLIGENCE}

\begin{abstract}
The objective of this study is to improvestudents' achievement in mathematics using quantum teaching model based on students' multiple intelligence. This study was an experimental study designed with pre-test and Post-test Group. The study population was class XI students of Department of Tata Boga at one of vocational schools in Padang which were selected through cluster random sampling. Data were obtained throughmultiple intelilligenceand pretest-posttest techniques. Questionnaire data were analyzed qualitatively and the pretest-posttest data were analyzed using a normalized gain scores. The results show that students' achievement in mathematics is improving after the learning process.
\end{abstract}

Keywords: Quantum Teaching, multiple intelligence, learning achievement

\section{PENDAHULUAN}

Tujuan pendidikan matematika pada jenjang pendidikan sekolah menengah adalah untuk memfokuskan pada penataan nalar dan pembentukan sikap siswa agar dapat menerapkan matematika dalam kehidupan. Tujuan pembelajaran matematika dapat tercapai apabila kegiatan pembelajaran matematika di sekolah berlangsung dengan baik. Dengan kata lain, metode mengajar perlu disesuaikan dengan gaya belajar siswa berdasarkan tipe kecerdasaan yang dimilikinya sehingga potensi siswa dapat digali dan dikembangkan.

Violinda (2012:3) menyatakan bahwa berdasarkan teori pembelajaran secara holistik bahwa proses pembelajaran yang berkualitas dapat terlaksana jika guru memiliki kemampuan untuk memahami karakteristik kecerdasan yang dimiliki oleh anak, dimana antara satu anak dengan anak lainnya berbeda karena setiap individu memiliki multiple intelligence. Dengan memahami kecerdasan yang dimiliki siswa, guru dapat mengakomodasi setiap siswa dengan berbagai macam pola pikirnya yang unik. Oleh karena itu, pembelajaran perlu melayani siswa secara individual untuk menghasilkan perkembangan yang sempurna pada setiap siswa.

Setiap orang mempunyai gaya belajar sendiri-sendiri dan tidak dapat dipaksakan untuk menggunakan gaya yang seragam. Di dalam kelas, beberapa siswa lebih suka terhadap guru yang mengajar dengan cara menuliskan segalanya di papan tulis, sehingga siswa bisa membaca dan memahaminya. Akan tetapi, beberapa siswa 
lain lebih suka guru yang mengajar dengan cara menyampaikannya secara lisan dan siswa mendengarkan agar bisa memahaminya. Sementara itu, ada siswa yang lebih suka membentuk kelompok kecil untuk mendiskusikan materi pelajaran. Nurani (2012:69) mengemukakan bahwa setiap anak harus mendapat perlakuan yang berbeda sesuai dengan potensi kecerdasannya masingmasing karena setiap individu memiliki cara yang berbeda untuk mengembangkan berbagai kecerdasan yang ada dalam dirinya.

Fleetham (Yaumi, 2012: 12) mengemukakan bahwa Multiple Intelligence atau kecerdasan jamak adalah berbagai keterampilan dan bakat yang dimiliki siswa untuk menyelesaikan berbagai persoalan dalam pembelajaran. Multiple Intelligence atau kecerdasan majemuk. Gardner mengemukakan bahwa kecerdasan jamak terdiri atas delapan tipe kecerdasan seperti disajikan pada Tabel 1.

Siswa dengan latar belakang kecerdasan yang berbeda-beda memiliki cara belajar yang berbeda-beda pula. Apabila guru mengajar tanpa memperhatikan multiple intelligence siswa, akan ada siswa yang kurang aktif dalam mengikuti proses pembelajaran, tidak terlibat dalam diskusi kelompok, atau tidak memperhatikan saat guru menerangkan. Akibatnya, banyak siswa yang mengalami kebingungan dalam menerima pelajaran matematika karena tidak mampu mencerna materi yang diberikan oleh guru. Pembelajaran matematika menjadi kurang menarik dan kurang menyenangkan bagi siswa. Oleh karena itu, guru perlu menerapkan model pembelajaran serta cara mengajar yang sesuai dengan gaya belajar siswa sehingga motivasi dan hasil belajar siswa dapat ditingkatkan.

Salah satu model pembelajaran yang membuka ruang bagi guru untuk dapat menerapkan berbagai cara mengajar yang mengakomodasi berbagai bentuk kecerdasan siswa adalah model Quantum Teaching. DePorter (2014:32) mengemukakan bahwa Quantum Teaching adalah penggubahan belajar yang meriah, dengan segala nuansanya, menyertakan segala kaitan, interaksi dan perbedaan yang memaksimalkan momen belajar. Guru dapat mempelajari keinginan dan harapan siswa sebagai dasar untuk memaksimalkan potensi yang mereka miliki melalui penggunaan model ini.

Kerangka rancangan belajar Quantum Teaching menurut DePorter (2014: 128) dikenal sebagai TANDUR, yaitu Tumbuhkan, Alami, Namai, Demonstrasi, Ulangi, dan Rayakan. Pada tahap Tumbuhkan, sertakan siswa dalam proses pembelajaran dengan memberitahu mereka manfaat yang bisa diperoleh (Apa Manfaatnya Bagiku?). Guru memberikan pengalaman baru kepada siswa pada Tahap Alami dengan memanfaatkan keinginan alami otak untuk mempelajari materi baru. Pada tahap Namai, guru membim-bing siswa untuk menemukan definisi, kata kunci ataupun konsep, memberikan identitas, serta mengurutkan. Penanaman konsep, mengajarkan keterampilan berpikir dan strategi belajar dibangun di atas pengetahuan dan keingintahuan siswa saat itu. Demonstrasi merupakan tahap dimana guru memberikan waktu dan kesempatan kepada siswa untuk menerjemahkan dan menerapkan pengetahuan siswa tentang materi yang baru saja

\section{Tabel 1. Delapan Tipe Kecerdasan Menurut Gardner}

\begin{tabular}{ll}
\hline \multicolumn{1}{c}{ Intelligences } & \multicolumn{1}{c}{ Description } \\
\hline Linguistic & $\begin{array}{l}\text { An ability to analyze information and create products involving oral and written } \\
\text { language such as speeches, books, and memos } \\
\text { An ability to develop equations and proofs, make calculations, and solve abstract } \\
\text { pogical- }\end{array}$ \\
$\begin{array}{l}\text { Mathematical } \\
\text { Spatial }\end{array}$ & $\begin{array}{l}\text { An ability to recognize and manipulate large-scale and fine grained spatial images } \\
\text { An ability to produce, remember, and make meaning of different patterns of sound }\end{array}$ \\
Musical & $\begin{array}{l}\text { An ability to identify and distinguish among different types of plants, animals, and } \\
\text { Neather formations that are found in the natural word }\end{array}$ \\
Bodily- & $\begin{array}{l}\text { An ability to use one's own body to create products or solve problems } \\
\text { kinesthetic }\end{array}$ \\
Interpersonal & $\begin{array}{l}\text { An ability to recognize and understand other people's moods, desires, motivations, } \\
\text { and intentions }\end{array}$ \\
Intrapersonal & $\begin{array}{l}\text { An ability to recognize and understand his or her own moods, desires, motivations, } \\
\text { and intentions }\end{array}$ \\
\hline Sumber: Davis, dkk (2012:6)
\end{tabular}


dipelajari ke dalam pembelajaran yang lain dalam kehidupannya. Tahap Ulangi dilakukan untuk mengetahui sejauh mana pemahaman siswa terhadap materi yang sudah dipelajari. Rayakan keberhasilan siswa dengan memberikan penghargaan untuk memberi rasa puas dengan menghormati usaha, ketekunan dan kesuksesan siswa.

Penelitian yang dilakukan oleh Martini, Rasna, dan Artawan (2014) menemukan kendala dalam penerapan metode quantum teaching adalah siswa yang memiliki kecerdasan dengan potensi yang berbeda-beda antara satu dengan yang lainnya. Pembelajaran yang dilakukan seharusnya memperhatikan perbedaan kecerdasan (multiple intelligence) tersebut. Sebagaimana diungkapkan oleh Tirtawati, Adnyana, dan Widiyanti (2014) bahwa metode pembelajaran kuantum menggunakan metodologi berdasarkan teori pendidikan, salah satunya adalah teori Multiple Intelligence.

Guru dapat merancang setiap bentuk interaksi, metode, dan strategi dalam penerapan quantum teaching yang sesuai dengan tipe kecerdasan yang dimiliki siswa sehingga guru dapat memasuki dunia siswa dan berdampak pada terbentuknya keunggulan.Huda dan Arief (2013:36) juga menyatakan bahwa pembelajaran yang melibatkan multiple intelligence berhubungan positif dengan prestasi belajar siswa pada aspek kognitif, afektif, dan psikomotor. Akan tetapi, hasil penelitian yang dilakukan oleh Rachmawati (2012:477) menunjukkan bahwa penerapan quantum teaching belum optimal dalam meningkatkan hard skill siswa tetapi sudah optimal dalam meningkatkan soft skill. Jadi, penerapan quantum teaching seharusnya memperhatikan multiple intelligence siswa sehingga proses pembelajaran yang dilakukan juga dapat meningkatkan hard skill. Oleh karena itu, penelitian penerapan quantum teaching melibatkan multiple intelligences dalam pembelajaran matematika ini dilakukan dengan tujuan untuk mengetahui apakah terjadi peningkatan prestasi belajar matematika siswa kelas XI SMK.

\section{METODE}

Penelitian ini merupakan penelitian eksperimen dengan rancangan Pre-test and Post-test Group. Populasi pada penelitian ini adalah siswa kelas XI Jurusan Jasa Boga salah satu SMK di Kota Padang. Penelitian membutuhkan sampel sebanyak satu kelas yang diambil secara acak dengan memperhatikan kesamaan rata-rata populasi. Hasil pengujian secara statistik menunjukkan bahwa populasi memenuhi asumsi kesamaan rata-rata sehingga pengambilan sampel dapat dilakukan secara cluster random sampling.

Instrumen yang digunakan dalam penelitian ini adalah angket Multiple Intelligences Research (MIR) dan soal pretes dan postes. Angket MIR bertujuan untuk mengetahui kecerdasan yang dominan dimiliki siswa, soal pretes dan postes berfungsi untuk mengukur peningkatan prestasi belajar matematika siswa.

Angket diberikan kepada siswa sebelum dilakukan proses pembelajaran menggunakan model Quantum Teaching. Angket MIR mencakup delapan kecerdasan yang dikemukakan Gardner. Setiap kecerdasan diwakili dengan 10 pernyataan. Angket MIR terdiri dari 80 pertanyaan yang harus dijawab oleh siswa dengan waktu yang sudah ditentukan selama 20 menit. Tes uji angket MIR dijawab oleh siswa secara individu, agar bisa diketahui kecerdasan masing-masing siswa dan tidak terpengaruh oleh temannya. Untuk mengetahui kecerdasan yang dominan dimiliki siswa, dilakukan perhitungan dengan cara menjumlahkan masing-masing skor siswa dari setiap kecerdasan, kemudian dilihat tiga skor yang tertinggi.

Data prestasi belajar siswa diperoleh berdasarkan hasil pretes dan postes yang dilakukan sebelum dan sesudah penerapan model pembelajaran Quantum Teaching. Analisis peningkatan hasil belajar siswa menggunakan rumus Gain Score dinormalisasi (Normalized Gain Score). Peningkatan hasil belajar dikategorikan tinggi apabila $g \geq 0,7$; termasuk kategori sedang apabila $0,3 \leq g<0,7$; dan kategori rendah apabila $g$ $<0,3$.

\section{HASIL DAN PEMBAHASAN}

Pengisian angket Multiple Intelligences Research (MIR) dilakukan oleh 20 orang siswa kelas sampel. Hasil perhitungan skor masingmasing siswa disajikan pada Tabel 2 .

Data pada Tabel 2 memperlihatkan tiga sampai empat kecerdasan dominan yang dimiliki siswa. Kecerdasan paling dominan di kelas sampel adalah kecerdasan interpersonal. Terdapat $82 \%$ siswa yang dominan pada kecerdasan tersebut. Ada satu siswa yang tidak memiliki kecerdasan interpersonal tetapi memiliki kecerdasan naturalis bersama 12 siswa lainnya. Di kelas sampel juga terdapat hanya satu siswa yang memiliki kecerdasan dominan spasial. Oleh karena itu, dalam 
penelitian ini digunakan strategi atau metode yang dapat mengakomodasi kecerdasan matematislogis, interpersonal, naturalis, dan spasial.

Tabel 2: Skor Kecerdasan Jamak Siswa

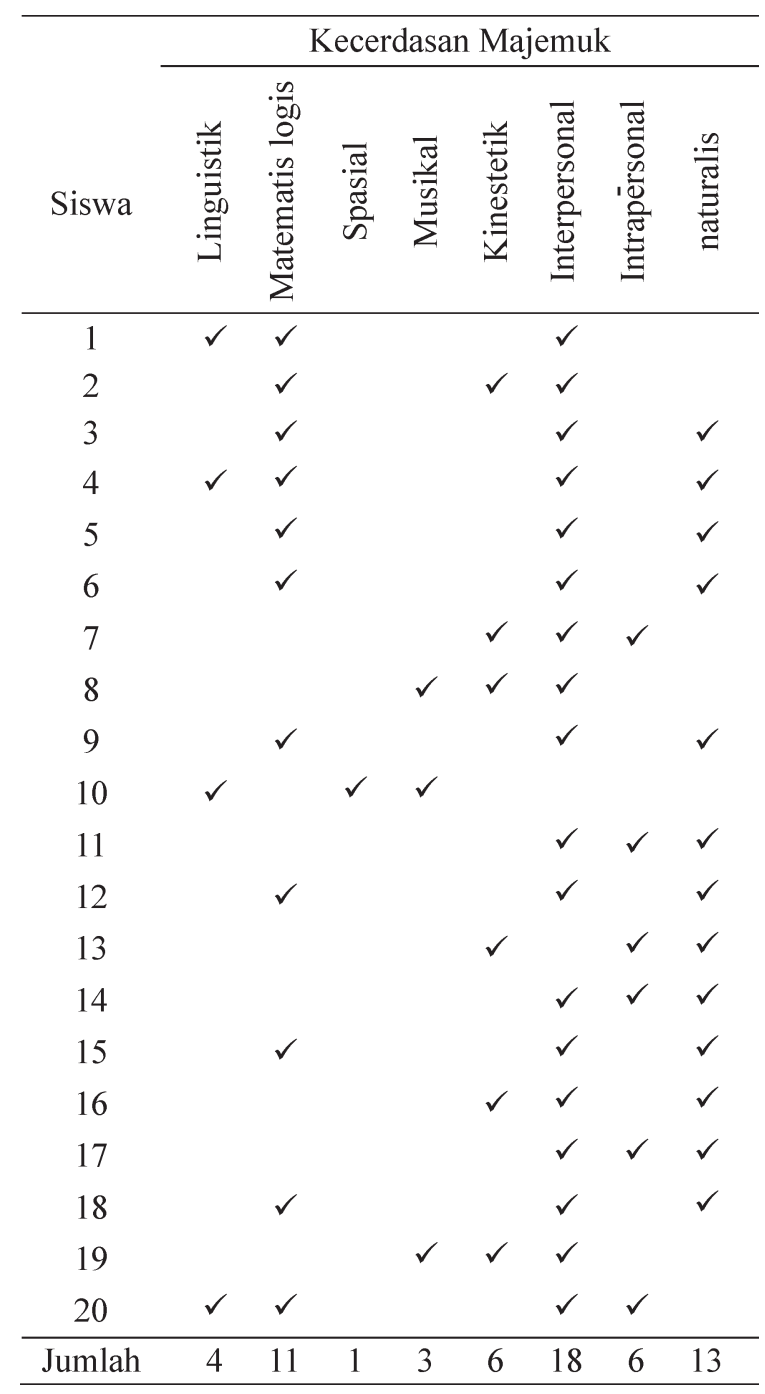

Sumber: Ronis (2000:51)

Pemilihan strategi atau metode pembelajaran yang dapat memfasilitasi keempat tipe kecerdasan tersebut dirancang dengan cara mempelajari prilaku yang relevan serta kegiatan belajar dan bentuk bahan ajar yang dibutuhkan. Kreativitas guru sangat diperlukan dalam menciptakan aktivitas belajar bermakna sehingga dapat menumbuhkembangkan kecerdasan majemuk peserta didik (2007). Strategi atau metode yang sesuai untuk empat tipe kecerdasan tersebut dijelaskan pada Tabel 3.

Model pembelajaran Quantum Teaching diterapkan dengan menggunakan strategi dan metode yang sesuai dengan perilaku yang relevan, kegiatan mengajar, dan bahan ajar yang dibutuh- kan. Pada tahap Tumbuhkan, guru memotivasi siswa dengan menyampaikan kompetensi yang akan dicapai siswa. Guru membuka pelajaran dengan menceritakan suatu masalah dan mengajukan pertanyaan mengarah pada materi yang berhubungan dengan alam sekitar dalam dunia siswa. Siswa dibawa keluar ruangan kelas untuk mempraktekkan soal cerita pada masalah yang diberikan. Guru meminta beberapa siswa dengan beberapa teman lainnya untuk memainkan peran pada masalah yang diberikan tersebut di luar ruang kelas sehingga dari penyelesaian permasalahan tersebut siswa mengetahui AMBAK (Apa Manfaatnya BAgiKu) dari materi yang sedang dipelajari.

Pada tahap Alami, guru memberikan suatu permasalahan yang ada dalam kehidupan nyata siswa, siswa terlibat langsung dalam penyelesaian permasalahan yang diberikan dan berinteraksi dengan teman untuk mengamati masalah serta mengaitkannya dengan pengetahuan yang sudah mereka miliki sebelumnya. Guru mendorong siswa untuk bertanya tentang materi. Siswa dibentuk dalam kelompok kerja yang beranggotakan 4 sampai 5 siswa dalam satu kelompok. Pada tahap Namai, kelompok diminta untuk mengumpulkan informasi, mengkaji tentang masalah terkait materi, melaksanakan penyelidikan masalah serta siswa dibimbing dalam kegiatan kelompok untuk membahas masalah dengan cara mengolah informasi (mengasosiasi) yang mereka dapatkan pada tahap sebelumnya. Pada tahap Demonstrasikan, siswa mengembangkan hasil diskusi kemudian mempresentasikantemuannya.

Pada tahap Ulangi, guru bersama siswa melakukan refleksi terhadap kegiatan pembelajaran yang sudah dilaksanakan untuk mengetahui sejauh mana pemahaman siswa terhadap materi yang dipelajari. Guru meminta siswa untuk membuat kesimpulan dari apa yang telah dipelajari dan menuliskan pada lembar yang disediakan dan mencentang lembar "Aku tahu bahwa aku memang tahu".Guru memberikan penghargaan, yaitu berupa penguatan verbal dan non verbal untuk menghormati usaha, ketekunan dan kesuksesan siswa. Penguatan verbal berupa pujian, pengakuan dan dorongan. Penguatan non verbal berupa hadiah alat tulis sepeti penggaris, pensil, pena dan penghapus.

Data hasil pretes dan postes matematika siswa pada kelas sampel dapat dilihat pada Tabel 4. Dari hasil pengujian normalitas data nilai 
pretes dan postes menggunakan uji KolmogorovSmirnov (KS) diperoleh nilai KShitung $_{\text {pretes }}=0,15$ dan KStabel $_{\text {pretes }}=0,28$, serta KShitung $_{\text {postes }}=0,10$ dan $K$ Stabel $l_{\text {postes }}=0,3$. Data ini menunjukkan bahwa KShitung $<$ KStabel, yang berarti bahwa data hasil tes siswa berdistribusi normal. Dengan demikian, teknik gain score dapat digunakan untuk menganalisis data hasil pretes dan postes.

Tabel 4. Rata-rata dan Gain Score Nilai Pretes dan Postes

\begin{tabular}{cccccc}
\hline Tes & $x_{\text {maks }}$ & $x_{\min }$ & $\bar{x}$ & $S$ & $\begin{array}{c}\text { Gain } \\
\text { score }\end{array}$ \\
\hline Pretes & 90 & 4 & 51,00 & 23,43 & 0,51 \\
Postes & 96 & 36 & 75,80 & 16,04 & (sedang) \\
\hline
\end{tabular}

Rata-rata nilai pretes dan postes matematika siswa kelas eksperimen mengalami peningkatan. Skor Gain yang dinormalisasi menunjukkan peningkatan prestasi belajar matematika dengan kategori sedang. Hal ini berarti bahwa prestasi belajar siswa mengalami peningkatan setelah diterapkan model pembelajaran Quantum Teaching yang melibatkan Multiple Intelligences.

Nilai pretes dan postes siswa dikelompokkan berdasarkan tipe kecerdasan dominan yang dimiliki. Pengelompokkan disusun berdasarkan tipe kecerdasan dominan yang difasilitasi dalam pembelajaran quantum teaching sehingga ada kelompok yang terfasilitasi pada dua dan tiga kecerdasan dominan serta ada juga yang hanya terfasilitasi pada satu kecerdasan dominan. Pengelompokkan nilai pretes dan postes berdasarkan tipe kecerdasan yang dominan dapat dilihat pada Tabel 5.

Grafik peningkatan nilai siswa berdasarkan tipe kecerdasan disajikan pada Gambar 1.

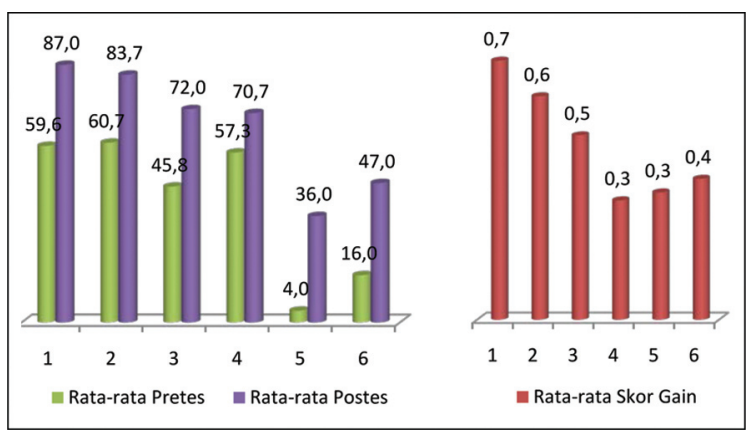

Gambar 1. Rata-rata Nilai Pretes, Postes, dan Skor Gain

Peningkatan nilai siswa pada setiap kelompok tipe kecerdasan yang dominan berada pada kategori sedang $(0,3 \leq g \leq 0,7)$. Peningkatan paling tinggi terdapat pada kelompok siswa yang memiliki tiga kecerdasan dominan dan peningkatan paling rendah diperoleh siswa memiliki satu tipe kecerdasan dominan yaitu siswa interpersonal dan siswa naturalis.

Metode yang digunakan guru untuk memfasilitasi siswa naturalis yaitu dengan membawa siswa ke luar ruangan cukup membuat siswa antusias. Akan tetapi, kegiatan yang dilakukan belum menghubungkan proses ataupun materi pelajaran dengan alam dan lingkungan sehingga siswa naturalis belum bisa memahami dengan baik materi pelajaran.

Kegiatan yang dilakukan guru dengan meminta beberapa siswa berdiri bersusun sehingga terbentuk susunan matriks sambil memegang media yang telah disediakan sangat memfasilitasi siswa matematis-logis dan siswa spasial. Media yang digunakan dapat dilihat pada Gambar 2.

\section{Tabel 5. Pengelompokkan Nilai Siswa Berdasarkan Tipe Kecerdasan Dominan}

\begin{tabular}{clcccc}
\hline Kelompok & Tipe Kecerdasan Dominan & $\begin{array}{c}\text { Jumlah } \\
\text { Siswa }\end{array}$ & $\begin{array}{c}\text { Nilai } \\
\text { Pretes }\end{array}$ & $\begin{array}{c}\text { Nilai } \\
\text { Postes }\end{array}$ & $\begin{array}{c}\text { Skor } \\
\text { Gain }\end{array}$ \\
\hline 1 & Matematis-logis, & 7 & 59,6 & 87,0 & 0,7 \\
& $\begin{array}{l}\text { Interpersonal, Naturalis } \\
2\end{array}$ & 3 & 60,7 & 83,7 & 0,6 \\
& $\begin{array}{l}\text { Matematis-logis, } \\
\text { Interpersonal }\end{array}$ & & & & \\
3 & Interpersonal, Naturalis & 5 & 45,8 & 72,0 & 0,5 \\
4 & Interpersonal & 3 & 57,3 & 70,7 & 0,3 \\
5 & Naturalis & 1 & 4,0 & 36,0 & 0,3 \\
6 & Spasial & 1 & 16,0 & 47,0 & 0,4 \\
\hline
\end{tabular}




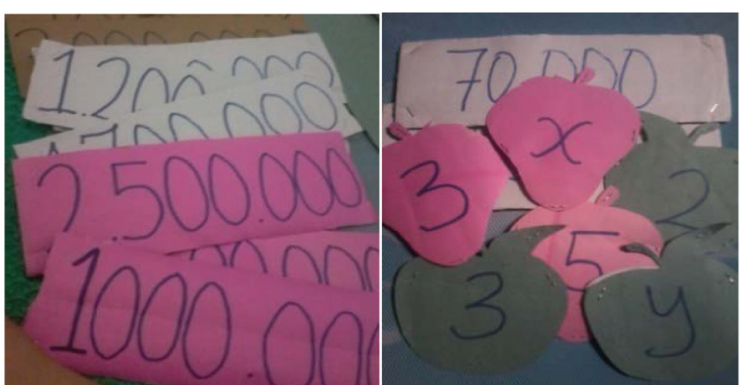

Gambar 2. Media Visual dalam Memperkenalkan Konsep Matriks

Siswa-siswa yang lain mengamati media yang dipegang temannya dan menentukan matriks-matriks yang terbentuk. Kegiatan ini sangat memfasilitasi satu-satunya siswa dengan tipe kecerdasan dominan spasial di kelas tersebut. Dilihat dari hasil tes, siswa tersebut termasuk kelompok yang memiliki prestasi belajar rendah pada mata pelajaran matematika. Akan tetapi, skor gain yang diperoleh siswa tersebut berada pada kategori sedang. Dengan kata lain, peningkatan yang terjadi cukup signifikan dan lebih tinggi daripada siswa naturalis dan siswa interpersonal-naturalis. Temuan ini didukung oleh Gardner (2011:10) yang menyatakan bahwa saat ini tidak dibutuhkan banyak orang yang memiliki kecerdasan tinggi atau kecerdasan ganda, yang dibutuhkan adalah individu yang dapat menggunakan kecerdasannya untuk tujuan-tujuan positif.

Kegiatan mengisi Lembar Tugas yang disediakan guru sangat memfasilitasi siswa matematis-logis. Contoh hasil kerja siswa dapat dilihat pada Gambar 3.

Kegiatan diskusi kelompok dan presentasi juga dilakukan untuk memfasilitasi siswa dengan kemampuan interpersonal yang merupakan kemampuan paling dominan di kelas sampel. Penggunaan masalah-masalah realistik seharusnya membantu siswa naturalis dalam memahami materi pelajaran, siswa interpersonal akan senang mengajarkan kepada temannya tentang apa yang dia ketahui, dan dibantu oleh siswa matematislogis untuk perhitungan yang lebih akurat.Akan tetapi, siswa belum bisa bekerja sama dan berinteraksi dengan baik. Kegiatan saling mengajar (tutor sebaya) yang dilakukan siswa belum berjalan dengan baik karena beberapa siswa sangat mendominasi kegiatan diskusi. Penelitian yang dilakukan oleh Aryani, Sudjito, dan Sudarmi (2015:6) juga menemukan siswa-siswa yang ingin mendominasi dalam pelaksanaan kegiatan kelompok yang diterapkan dalam pembelajaran yang telah dirancang sesuai dengan teori multiple intelligence.

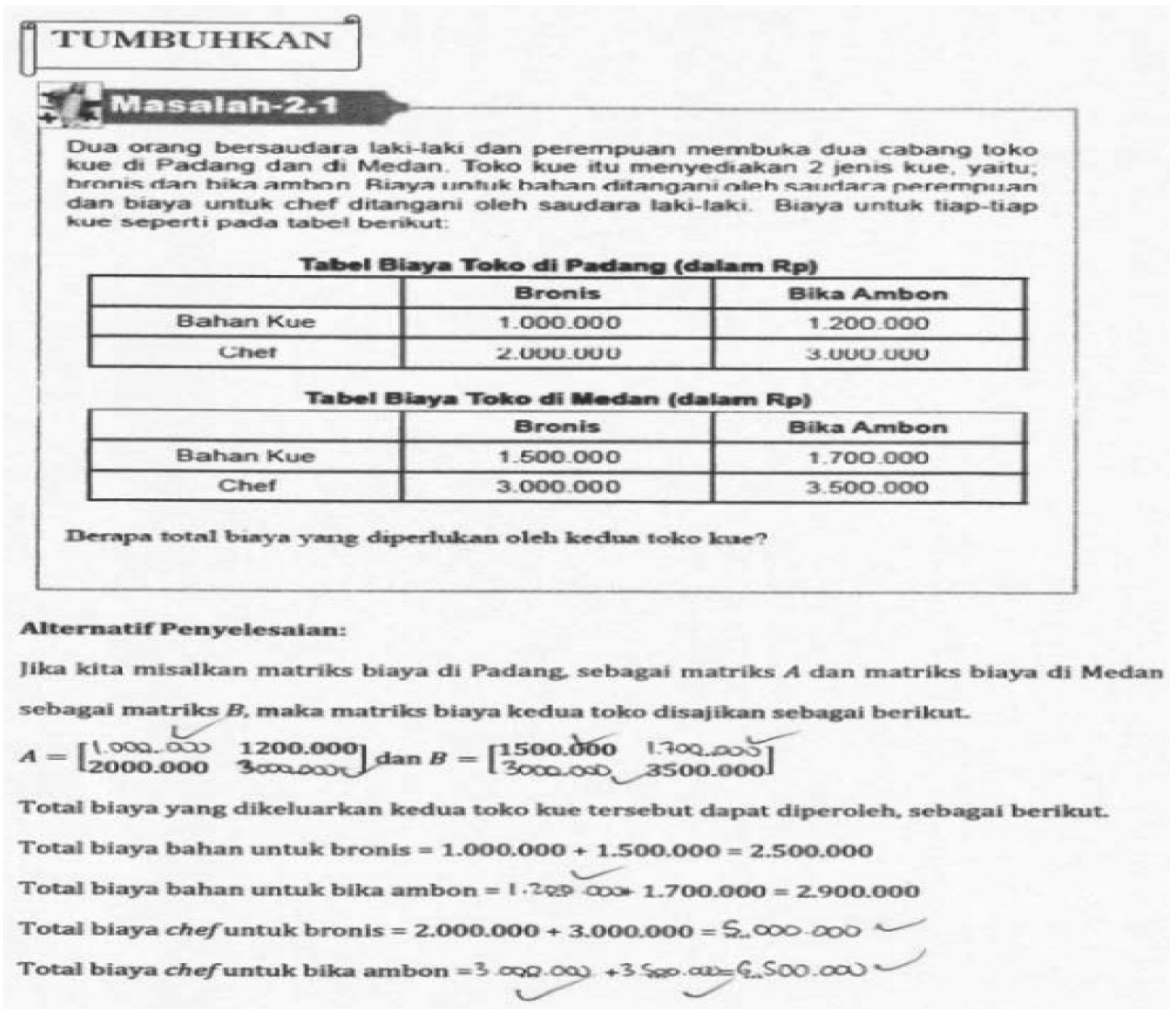

Gambar 3. Lembar Tugas Siswa 


\section{PENUTUP}

Berdasarkan hasil dan pembahasan, pembelajaran quantum teaching yang telah dilaksanakan telah berhasil meningkatkan prestasi belajar siswa. Peningkatan paling signifikan terjadi pada siswa yang memiliki kecerdasan dominan matematislogis, interpersonal, dan naturalis. Dengan demikian, disarankan beberapa hal, yaitu: (1) untuk memfasilitasi metode dan strategi pembelajaran di kelas berdasarkan tipe kecerdasan (multiple intelligences) yang dimiliki siswa agar prestasi belajar siswa mengalami peningkatan; (2) pembelajaran yang bersifat kontekstual dan realistik dapat memfasilitasi siswa dengan tipe kecerdasan naturalis apabila siswa berada langsung di alam atau lingkungan yang terkait dengan materi pelajaran, 3) kegiatan belajar tutor sebaya atau kerjasama kelompok yang memfasilitasi siswa interpersonal perlu memperhatikan prinsip-prinsip pembelajaran kooperatif.

\section{UCAPAN TERIMA KASIH}

Ucapan terima kasih ditujukan kepada: 1) Ibu Villia Anggraini, M.Pd., Ibu Alfi Yunita, M.Pd, dan Ibu Ainil Mardiyah, M.Si atas sumbang saran yang telah diberikan dalam pelaksanaan penelitian ini, 2) Mitra Bestari dan Tim Editing Cakrawala Pendidikan yang banyak memberikan masukan dalam penulisan artikel ini.

\section{DAFTAR PUSTAKA}

Aryani, Agustin Dwi, Sudjito, Debora Natalia, dan Sudarmi, Marmi. 2015. "Penerapan Model Pembelajaran Berdasarkan Teori Multiple Intelegence (MI) yang Dominan dalam Kelas Pada Materi Tekanan". Jurnal Radiasi,06 (1):1-10.

Davis, Katie, dkk. 2012. "The Theory of Multiple Intelligences". Online: https://howardgardner01.files.wordpress.com/2012/06/443davis-christodoulou-seider-mi-article.pdf

DePorter, Bobbi, Reardon, Mark \& SingerNourie, Sarah. 2014. Quantum Teaching. Bandung: PT Mizan Pustaka.

Gardner, Howard. 2011. "The Theory of Multiple Intelligences: As Psychology, as Education, As Social Science". Online: https://howardgardner01.files.wordpress. com/2012/06/473-madrid-oct-22-2011pdf.

Hake, Richard R. 1998. "Interactive-engagement Versus Traditional Methods: A Six-thousand-student Survey of Mechanics Test Data for Introductory Physics Courses". Jurnal Department of physics, Indiana University, Bloomington, No. 1.

Huda, Miftachul, dan Arief, Alimufi. 2013. "Pengaruh Multiple Intelligences Menggunakan Model Pembelajaran Kooperatif Tipe Jigsaw terhadap Hasil Belajar Siswa pada Pokok Bahasan Listrik Dinamis Kelas X Di SMAN 1 Porong". Jurnal Inovasi Pendidikan Fisika, 02 (03): 34 - 37.

Martini, Ni Made, Rasna, I Wayan, dan Artawan, I Gede. 2014.'Implementasi Model Pembelajaran Quantum Learning dalam Pembelajaran Menulis Karangan Deskripsi pada Siswa Kelas X SMKN 1 Abang". e-Journal Program Pascasarjana Universitas Pendidikan Ganesha Program Studi Pendidikan Bahasa dan Sastra Indonesia, vol. 3.

Nurani, Yuliani. 2012. "Pengembangan Media Daur Ulang Berbasis Kecerdasan Jamak dalam Peningkatan Keterampilan HidupAnak Usia Dini”. Cakrawala Pendidikan, XXXI (1), 67-81.

Rachmawati, Rima. 2012. "The Implementaton Quantum Teaching Methodof Graduate Through Up-Grade Hard Skill and Soft Skill(Case study on Management Accounting Class)". Procedia--Social and Behavioral Sciences, 57: 477 - 485.

Tirtawati, Ni Luh Ratna, Adnyana, Putu Budi, dan Widiyanti, Ni Luh Putu Manik.2014. "Pengaruh Pembelajaran Kuantum (Quantum Learning) dan Peta Pikiran (Mind Mapping) terhadap Keterampilan Berpikir Kreatif dan Hasil Belajar Biologi Siswa SMA. e-Journal Program Pascasarjana Universitas Pendidikan Ganesha Program Studi IPA,Vol. 4.

Violinda, Qristin. 2012. "Implementasi metode smart learning solution berdasar teori 
multiple inteligence dalam pengembangan potensi anak usia dini". Indonesian Journal of Early Childhood Education Studies, 1(1): 1-6
Yaumi, Muhammad. 2012. Pelajaran Berbasis Multiple Intelligences. Jakarta: PT Dian Rakyat. 